\title{
Vibration-enhanced droplet motion modes: Simulations of rocking, ratcheting, and ejection
}

\author{
Ryan A. Huber ${ }^{1}$, Matthew Campbell ${ }^{2}$, Nicole Doughramaji ${ }^{1}$, Melanie M. Derby ${ }^{1^{*}}$ \\ ${ }^{1}$ Department of Mechanical and Nuclear Engineering, Kansas State University, Manhattan, KS
}

USA

${ }^{2}$ Institute for Environmental Research, Kansas State University, Manhattan, KS USA

*Corresponding author: derbym@ksu.edu, 785-532-2606

\begin{abstract}
Power plant water usage is a coupling of the Energy-Water nexus; this research investigates water droplet motion, with implications for water recovery in cooling towers. Simulations of a 2.6-mmdiameter droplet motion on a hydrophobic, vertical surface (i.e., advancing and receding contact angles of $120^{\circ}$ and $60^{\circ}$ ) were conducted in XFlow using the lattice Boltzmann method. Results were compared to two experimental cases with $x$ - and $y$-direction vibrations; in the first case, experimental and simulated droplets experienced $30-\mathrm{Hz}$ vibrations (i.e., $\pm 0.1 \mathrm{~mm} x$-direction amplitude, $\pm 0.2 \mathrm{~mm} y$-direction amplitude) and the droplet ratched down the surface. In the second case, $100-\mathrm{Hz}$ vibrations (i.e., $\pm 0.8 \mathrm{~mm} x$-direction amplitude, $\pm 0.2 \mathrm{~mm} y$-direction amplitude) caused droplet ejection from the vibrating surface. Simulations were then conducted for a wide range of frequencies (i.e., $10-100 \mathrm{~Hz}$ ) and amplitudes (i.e., $\pm 0.036-100 \mathrm{~mm}$ ), resulting in accelerations of $0.197-1970 \mathrm{~m} / \mathrm{s}^{2}$. Under low accelerations (e.g., $<7 \mathrm{~m} / \mathrm{s}^{2}$ ) droplets rocked upwards and downwards in rocking mode, but did not overcome the contact angle hysteresis and, therefore, did not move. As acceleration increased, droplets overcame the contact hysteresis and entered ratcheting mode. For vibrations which prompted droplet motion, droplet velocities varied
\end{abstract}


between $10-1000 \mathrm{~mm} / \mathrm{s}$ and higher velocities were found at higher accelerations. It was noted that both $x$ - and $y$-direction vibrations were required for droplet ejection.

Keywords: Energy-water, droplet shedding, cooling towers, contact angle hysteresis, vibrations

\section{Introduction}

The Energy-Water nexus emphasizes the tradeoffs between energy production and water consumption [1, 2]; this is particularly challenging during hydrologic droughts [3] or in locations with limited water availability [4]. Power plants are an important target for water conservation because U.S. power production accounted for $40 \%$ of freshwater withdrawals and $3 \%$ of freshwater consumption in 2010 [5]. Strategies for reducing power plant water usage include dry cooling [6, 7] and capturing drift loss from the moist air in a cooling tower via meshes [8] or an electric field [9]; capturing cooling tower water is the focus of this work. Ghosh et al. [8] placed a simple wire mesh fog collector inside a 500 MW power plant cooling tower and were able to retrieve up to $54 \mathrm{~L} / \mathrm{m}^{2}$ of water, outperforming water collected via fog collectors (e.g., $1-12 \mathrm{~L} / \mathrm{m}^{2}$ [10-13]) due to the moist cooling tower environment. Ghosh et al. [8] estimated that they could save $40 \%$ of the drift loss with their mesh fog collectors, about $10.5 \mathrm{~m}^{3} / \mathrm{hr}$ for their test plant. Damak and Varanasi [9] moved fog droplets using an electric field and modeled the deposition efficiency for single and double wires. Their electrostatic approach required high voltages (e.g., $10 \mathrm{kV}$ ) but very low currents, resulting in low total energy consumption and outperformed water collection from a typical wire mesh in experiments.

Droplet shedding is a critical mechanism in water/fog collectors and condensers, thereby providing an interesting opportunity for droplet shedding from induced motion to improve performance. Various droplet removal methods have been investigated in the literature. The most 
basic form of droplet removal is gravitationally driven droplets on a tilted surface [14,15]. Another method is surface tension gradients to drive the droplets in a certain direction [16, 17]. Surface vibrations have also been shown to motivate the droplets to move [18-25]; vibrations can be combined with the previous two methods to further improve the droplet motion [26] and reduce droplet departure diameters from $4-7 \mathrm{~mm}$ to $1-3 \mathrm{~mm}$ via imposed vibrations (i.e., frequency $f=100$ Hz, amplitude $A=0.4 \mathrm{~mm}$ ) [27].

Researchers investigated droplets on horizontal surfaces with applied vibrations [20-25, 28-30]. Daniel et al. [21] studied 1-2 mm diameter droplets on a horizontal surface with vibrations (i.e., $f=50-100 \mathrm{~Hz}, A=0.22 \mathrm{~mm}$ ). They modeled the droplet as a spring with deformation caused by the frictional forces acting on the three-phase contact line and vibrational force prompting the droplet to move. When asymmetric periodic vibrations were applied to the surface the droplet deformed but the force of the friction and the formed contact angle hysteresis held the droplet in place unless a significant amplitude was applied for a given frequency. However, when the amplitude grew large enough to overcome the hysteresis in both forwards and reverse directions, the droplet could reverse its direction. This concurred with the research by Brunet et al. [19] that noted certain vibrational conditions (e.g., $f=100 \mathrm{~Hz}, A=17.4 \mathrm{~mm}$ ) caused a $5-\mu \mathrm{L}$ water droplet to climb up a tilted surface. Dong et al. [22] showed the different vibrational modes of water droplets on a horizontal surface including rocking and ratchet modes. Regions were found for different vibrational modes based on vibration frequency and droplet mass.

Combined vibrated surfaces and surface features can prompt and guide droplet motion. Mettu et al. [23] studied the effects of surface tension gradients created by surface-coatings (e.g., PDMS, Hydrocarbon, and Polystyrene on silicon wafers) on droplet motion induced by $100 \mathrm{~Hz}$, $3.3 \mathrm{~mm}$ vibrations. They found that small (e.g., $2^{\circ}$ ) and large (e.g., $23^{\circ}$ ) contact angle hystereses 
(i.e., the difference between advancing and receding contact angles) yielded no movement while a medium (e.g., $8^{\circ}$ ) contact angle hysteresis allowed the droplet to move on the horizontal surface. Quéré [14] noted that a low contact angle hysteresis was required for droplet motion on most wetting surfaces. Surface structures and the surface tension gradients they form can impact droplet motion. Bormashenko et al. [28] showed that on a rough surface, vibrations will cause the droplet to transition from a pure Cassie wetting state to a pure Wenzel wetting state and the work by Shastry et al. [30] observed that when a structured surface tension gradient was applied to a surface, it was possible to control the path that a droplet will take.

The problem of a liquid droplet moving dynamically on a solid surface is a common occurrence observed in engineering systems; however, from a physical modeling standpoint it is deceptively complex. Many mathematical challenges must be overcome to model this problem accurately. The formulation must include multiphase capability to resolve the three phases (i.e., liquid, gas, and solid) and must utilize transient formulation to capture droplet dynamics. Modeling the 'moving contact line' (MCL) where a liquid, gas and solid meet is currently an active area of study [31-35]. It is well known that the liquid contact angle experiences hysteresis and can vary from a minimum (receding) angle to a maximum (advancing) angle, but existing codes do not always fully account for this effect. Further, at macro, and mesoscopic scales the MCL is a mathematical singularity that must be handled with empirical formulations, making a generalized, physically accurate model difficult.

The research objectives of this work are to determine the effects of vibrations on water droplet motion on a hydrophobic, vertical surface; this includes identifying different droplet motion regimes and the ability of vibrations to overcome contact angle hysteresis. Simulations were conducted using XFlow for different test conditions, including the influences of $x$ - and $y$ - 
direction vibrations for a range of frequencies (i.e., 10-100 Hz) and amplitudes (i.e., 0.036-100 $\mathrm{mm})$, resulting in accelerations of $0.197-1970 \mathrm{~m} / \mathrm{s}^{2}$.

\section{Simulations}

The research focus of this study is to investigate the dynamic behavior of liquid droplets on a vibrating, solid substrate. This research does not include the development of methods and codes to model this problem; therefore, the use of established simulation tools was necessary. Many commercial Computational Fluid Dynamics (CFD) codes based on the finite volume method do not have provision for contact angle hysteresis and struggle to accurately resolve the multiphase solutions in the near-wall region with accuracy. CFD solutions based on the lattice Boltzmann method (LBM) can handle these complexities well. The LBM is an emerging tool in CFD applications due to inherent advantages of the method, including:

- Well-posed and accurate handling of multi-phase and multi-component flows.

- Complex boundaries are handled easily.

- Simulations can be parallelized efficiently allowing the use of fine resolution, small timesteps and advanced turbulence models (LES) [36].

After consideration of many commercial CFD codes, XFlow, based on the LBM, was determined to be well suited to handle a dynamic droplet with MCL including the ability to specify advancing and receding contact angles. Initial studies showed good correlation between simulations and experiments providing confidence the implementation of the LBM in XFlow could be effectively utilized as a tool to study droplet dynamics on a vibrating, solid substrate.

\subsection{XFlow methodology}

XFlow, a commercial multiphase CFD code based on the LBM, was selected for simulating water droplet motion on a vertical surface due to vibrations. The LBM solves the Boltzmann 
equation and collision models to simulate Newtonian fluid flow, and has successfully simulated a range of flow conditions, including porous media, human blood flow, vortex shedding, and multiphase flows [37-41].

\subsubsection{Lattice structure}

The lattice structure of LBM works by discretizing a Cartesian space into a set number of discrete points with a discrete set of velocity directions. The different lattice structures use the naming scheme DnQm, where $n$ is the dimension of a problem and $m$ represents the number of velocity directions, including no velocity. For three-dimensional cases, XFlow uses the D3Q27 lattice scheme, which XFlow organizes in an octree structure. The use of this lattice scheme provides a fourth-order spatial discretization in return for higher computational cost [42].

\subsubsection{Geometry modeling}

XFlow uses the Wall-Adapting Local Eddy (WALE) viscosity model of LES to model turbulence. This provides a consistent local eddy-viscosity and near wall behavior. In the LBM, the strain rate tensor is locally available, which allows for efficient implantation of LES models. In addition to the WALE model XFlow also uses wall functions in order to model the boundary layer, the Wall-Modeled LES approach (WMLES) [42]. A generalized law of wall given by Shih et al. [43] models the boundary layer. To discretize the geometry XFlow projects a set of discrete velocities onto the geometry tessellation. Since each lattice node can detect up to 27 geometry projections, a high level of detail is provided for the geometry discretization. The flexibility of the octree structure and the WMLES allows XFlow to address the fluid-structure interaction; this also allows for dynamic geometries, such as the vibrating surface and water droplet observed in this work. The method used by this paper is to enforce the geometries' orientation based on user defined equations. To accomplish this, XFlow updates the lattice structure every time step to mark 
lattice nodes as either fluid or solid. The discrete velocities are projected every time step as well to determine the new distance to the wall. The boundary conditions in XFlow are resolved using the bounce-back method, in which the incoming PDFs at the wall node are reflected back to the fluid node [42].

\subsubsection{Fluid modeling}

XFlow utilizes the Boltzmann transport equation in the continuum space with discrete velocities,

$$
\frac{\partial F_{i}}{\partial t}+e_{i} \cdot \nabla F_{i}=\Omega_{i} i=1, \ldots, b
$$

where $F_{i}$ are the probability distribution functions, $e_{i}$ are the velocity vectors and $\Omega_{i}$ are the collision operators. XFlow's collision operator is implemented in central momentum space. The raw moments are defined as,

$$
\tilde{\mu}_{x^{k} y^{l} z^{m}}=\sum_{i}^{N} F_{i}\left(e_{i x}-u_{x}\right)^{k}\left(e_{i y}-u_{y}\right)^{l}\left(e_{i z}-u_{z}\right)^{m}
$$

where $u$ is the macroscopic velocity vector, $\mu$ is the raw moment, and $k, l$, and $m$ are the orders of moments taken in $x, y$, and $z$ directions respectively. XFlow's collision operator is based on a multiple relaxation time scheme shown in equation (3),

$$
\Omega_{i}^{M R T}=-M_{i j}^{-1} \hat{S}_{i j}\left(\mu_{i}^{e q}-\mu_{i}\right)
$$

Where $M$ is the transformation matrix, $\hat{S}$ is the diagonal relaxation matrix, and $\mu^{\mathrm{eq}}$ is the raw moment at equilibrium. XFlow uses the Chapman-Enskog expansion to identify the kinematic viscosity, $v$, with the relaxation time, $\tau$, and speed of sound, $c_{s}$, as seen in equation (4), 


$$
v=c_{s}^{2}\left(\tau-\frac{1}{2}\right)
$$

The use of the Chapman-Enskog expansion demonstrates that the LBM is second-order accurate in space [42].

\subsection{Simulation parameters}

In order to simulate droplet motion on a vibrating surface, domains of $X-1.5 \mathrm{~mm}, Y$-5mm (or $Y$-62mm for faster-moving droplets), and Z-3mm were used to capture the droplet physics. In each simulation, the volume fractions in the domain were initially assigned as air or water (i.e., a single 2.6-mm-diameter hemisphere of water was initialized on a vertical hydrophobic wall); the initial droplet volume was maintained throughout the simulations. Water and air densities were based on an ambient temperature of $20{ }^{\circ} \mathrm{C}$. A sinusoidal position function was enforced on the domain defined in equations (5) and (6), resulting in accelerations given by equations (7) and (8), respectively,

$$
\begin{gathered}
x=A \cos (2 \pi f t) \\
y=-B \cos (2 \pi f t) \\
\ddot{x}=4 \pi^{2} f^{2} B \cos (2 \pi f t) \\
\ddot{y}=4 \pi^{2} f^{2} B \cos (2 \pi f t)
\end{gathered}
$$

where $A$ was the $x$-amplitude, $B$ was the $y$-amplitude, $f$ was frequency, and $t$ was time; the $x$-axis was perpendicular to the vertical wall and the $y$-axis was parallel to the vertical wall. Gravity was applied in the negative $y$ direction. Cases simulated included those with both $x$ - and $y$-direction vibrations, as well as only $y$-direction simulations. Droplets were generally simulated for three periods of induced vibration (i.e., 0.01-0.3 sec); a few high frequency (e.g., $100 \mathrm{~Hz}$ ) or high 
amplitude (e.g., $100 \mathrm{~mm}$ ) cases were simulated for one period due to the sizable droplet motion and large computational costs (i.e., simulations required multiple days even when conducted on 28 parallel cores). The time step for the simulation was determined by equation (9) where the velocity was $1 \mathrm{~m} / \mathrm{s}$ or $10 \mathrm{~m} / \mathrm{s}$ if the average downward velocity of the drop was greater than $1 \mathrm{~m} / \mathrm{s}$.

$$
S_{v}=u \frac{\Delta t}{\delta}<.1
$$

Where $S_{v}$ was defined as a stability parameter used to determine if the simulation satisfies the Courant-Friedrichs-Lewy condition, $u$ was the maximum velocity, $\Delta t$ was the time step, and $\delta$ was the resolved scale. To allow for a contact angle hysteresis, the advancing $\left(120^{\circ}\right)$ and receding $\left(60^{\circ}\right)$ contact angles were assigned independently based on experimental data of a $2.6 \mathrm{~mm}$ diameter drop moving down a vertical Teflon surface, as seen in Figure 1.

\subsection{Grid independence study}

A grid independence study, using kinetic energy as the variable, was conducted to ensure the size of the grid did not significantly affect simulation results. Figure 2 shows the kinetic energy of the water drop over time for five different resolved scales, $D / N$, where $D$ was defined as the initial water droplet diameter of $2.6 \mathrm{~mm}$ and $N$ equaled 30, 40,50, 75, and 100 elements across the diameter. There was good agreement between the kinetic energy results from the $D / 50$ (i.e., element spacing $=0.052 \mathrm{~mm}$ ) mesh and the finest mesh, 3.5\% difference in kinetic energy rootmean-square value; therefore, the $D / 50$ mesh was selected in order to minimize simulation time; one period on 28 cores took 16 hours.

\subsection{Experimental validation of simulations}


For validation purposes, simulations were conducted for two experimental droplet motion cases using the experimental approach reported in Chen et al. [44]. In these experiments, $x$ - and $y$ vibrations were applied to a Teflon film via an eccentric mass motor and $2-\mu \mathrm{L}$ droplets (i.e., nominal diameter of $2.66 \mathrm{~mm}$ for a hemisphere) were placed on the vibrating surface and observed using a high speed camera (Fastec IL3 camera with Leica Z16 APO lens) at a rate of 500 frames per second. In the first experimental case, the vibrational frequency was $30 \mathrm{~Hz}$, and the $x$ and $y$ amplitudes were $\pm 0.1 \mathrm{~mm}$ (i.e., $x$ acceleration of $3.55 \mathrm{~m} / \mathrm{s}^{2}$ ) and $\pm 0.2 \mathrm{~mm}$ (i.e., $y$ acceleration of $7.11 \mathrm{~m} / \mathrm{s}^{2}$ ), respectively. These parameters were duplicated in the simulation. Figure 3a shows the water droplet during the experiment and Figure 3b shows the water droplet from the simulations. The water droplet was forced into ratchet motion by the vibrations and the average downward velocities, defined as total distance moved over the simulated time, of the droplets were $16 \pm .14$ $\mathrm{mm} / \mathrm{s}$ and $15 \mathrm{~mm} / \mathrm{s}$ for the experimental and simulated droplets, respectively. From the observations of the deformation and measurement of the velocities, it was determined that the simulations were capable of capturing the behavior of droplet motion (i.e., ratcheting) observed in this experiment.

Experiments were also conducted for an experimental case in which a $2-\mu \mathrm{L}$ water droplet was ejected from the surface. For this case, a frequency of $100 \mathrm{~Hz}$ with $x$ - and $y$-amplitudes of \pm $0.4 \mathrm{~mm}$ (i.e., $x$ acceleration of $158 \mathrm{~m} / \mathrm{s}^{2}$ ) and $\pm 0.15 \mathrm{~mm}$ (i.e., $y$ acceleration of $59 \mathrm{~m} / \mathrm{s}^{2}$ ), respectively; these conditions were applied for the simulation as well. The results are shown in Figure $4 \mathrm{a}$ for the experimental test and Figure $4 \mathrm{~b}$ for the simulation. The ejection of the water droplet is very similar, and the average downward velocities before ejection were $41 \pm .45 \mathrm{~mm} / \mathrm{s}$ and $40 \mathrm{~mm} / \mathrm{s}$ for the experimental and simulated velocities, respectively. Excellent agreement was shown between simulations and experiments for both the ratcheting and ejecting cases. 


\section{Results and discussion}

Four droplet motion modes (i.e., rocking, ratcheting, pumping, and ejecting) were observed and are defined in section 3a. Simulations provide a decoupling of parameters that can be difficult to achieve in experiments, including the impacts of $x$ - and $y$-direction vibrations compared to $y$ direction vibrations alone (section 3b) and impacts of acceleration (section 3c). Further analysis (section 3d) was conducted to determine the major factors of droplet motion.

\subsection{Definition of droplet motion modes}

Four different modes of droplet motion due to vibrations were observed in simulations: rocking, ratcheting, pumping, and ejection. A brief description of these modes follows, and simulation results are presented in subsequent sections. In the rocking mode, the contact line of the droplet does not slip; the droplet simply rocks back and forth without an average downward velocity. The ratcheting mode is similar to rocking in that the droplet rocks back and forth; however, this motion causes the contact line of the droplet to slip, and the droplet will have a downward velocity, while ratcheting back and forth [22-25]. In pumping, the droplet flattens and elongated in sync with the periodic nature of the vibrations while the contact line remains pinned [25]. In the droplet ejection mode, vibrational forces are sufficiently large and the droplet elongates to a point where the surface tension forces can no longer maintain the droplet and a portion of the droplet breaks off from the surface [44, 45].

Droplet modes differed based on vibrations imposed in experiments and simulations. Rocking and ratchet were primarily due to vibrational forces in the $y$-direction, while pumping and ejection were only seen when a combination of vibrational forces in the $x$ - and $y$-directions. When 
vibrational force vector had components in both the $x$ - and $y$-directions, a combination of modes was observed in the droplets.

\subsection{Impacts of vibration direction (i.e., $x$ - and $y$-direction vibrations compared to only $y$ - direction vibrations)}

Previous experiments incited droplet motion due to $x$-direction and $y$-direction vibrations [44] and different vibrational parameters can be explored through simulations (e.g., vibrational forces purely in one direction). This allows for a comparison to be made to determine if $x$-direction vibrations aid in the shedding of droplets or consume energy without contributing to droplet motion. Simulations were conducted using the same vibrational frequencies and $y$-direction amplitudes as the validation tests, but with zero amplitude in the $x$-direction.

Images from simulations $(f=30 \mathrm{~Hz})$ with $x$-direction $( \pm 0.1 \mathrm{~mm})$ and $y$-direction $( \pm 0.2$ $\mathrm{mm})$ amplitude vibrations and only $y$-direction $( \pm 0.2 \mathrm{~mm})$ amplitude vibrations are shown in Figure 5a and Figure 5b, respectively. The droplets in both simulations move in the negative $y$ direction due to the ratcheting mode; however, the droplet with combined $x$-direction and $y$ direction motion briefly displays some of the pumping mode as well; the droplet in Figure 5a is slightly flattened compared to the droplet in Figure $5 \mathrm{~b}$ in the fifth frame. The average downward velocity of the drops was calculated and the droplet with only a $y$-vibrational force experienced a downward velocity of $11 \mathrm{~mm} / \mathrm{s}$ compared to $15 \mathrm{~mm} / \mathrm{s}$ for the droplet with $x$ - and $y$-vibrational forces.

This comparison was also conducted for the simulations at a frequency of $100 \mathrm{~Hz}$. The images of the $x( \pm 0.4 \mathrm{~mm})$ and $y( \pm 0.2 \mathrm{~mm})$ amplitude vibrations and the $y$-only amplitude vibrations are shown in Figure 6a and Figure 6b, respectively. Two different modes of droplet 
motion are observed. The droplet with $x$ - and $y$-vibrations ratchets down the surface and then ejects from the vibrating surface, while the droplet with only $y$-vibrations ratchets downward but does not eject. The average downward velocity was significantly larger for the droplet with only a $y$ vibrational force than the droplet with $x$ - and $y$-vibrational forces for the $100 \mathrm{~Hz}$ vibrational frequency, with velocities of $60 \mathrm{~mm} / \mathrm{s}$ and $40 \mathrm{~mm} / \mathrm{s}$, respectively. In this case, $x$-direction vibrational forces reduced the average downward velocity of the droplets. Additionally, droplet shedding through ratcheting is likely a more beneficial mechanism for condensation as sweeping droplets can clear droplets below the departing droplet, leaving new surface area clear for nucleation [46, 47]. The subsequent section (3c) investigates the impacts of only $y$-directional vibrations on droplet motion.

\subsection{Impacts of acceleration on droplet motion}

Based on Newton's law, a droplet pinned to a vertical surface requires an external force to initiate movement. In these vibrating cases, the force is provided by the acceleration of the surface. For droplets of the same size, the larger the acceleration of the surface, the larger the acting force, and thus resulting droplet velocities may be greater. There are several ways for the vibrational forces to cause the droplet to move. The first is to use a force large enough to overcome the imbalance of pinning forces in the y-direction caused by the contact angle hysteresis, while another approach is to reduce the contact angle hysteresis to $0^{\circ}$. When this occurs, the pinning forces will be perfectly balanced in the $\mathrm{y}$-direction and the resultant force will be only in the $\mathrm{x}$-direction. This means that gravity will not have any opposing forces and the droplet will begin to move.

Figure 7a shows the average downward velocities of the simulations run with a frequency of $10 \mathrm{~Hz}$ over a range of accelerations, $7.11 \mathrm{~m} / \mathrm{s}^{2}, 0.197 \mathrm{~m} / \mathrm{s}^{2}$, and $59.2 \mathrm{~m} / \mathrm{s}^{2}$, in Figure $7 \mathrm{~b}, \mathrm{c}$, and d, respectively. As expected, the larger the acceleration is, the faster the water droplet moves. 
However, there are two cases for the $10 \mathrm{~Hz}$ vibrations that do not produce any downward velocity (i.e., $0.197 \mathrm{~m} / \mathrm{s}^{2}$, seen in Figure 7c, and $1.97 \mathrm{~m} / \mathrm{s}^{2}$, not pictured); these two rocking motions are shown as red triangles on the graph in Figure 7a. In these cases, the vibrations are strong enough to shake the droplet slightly but not strong enough to overcome the surface pinning forces.

Generating large accelerations at low frequencies requires very large amplitudes. In the acceleration equation (8), the frequency term is squared whereas the amplitude term is proportional. To create large accelerations at low amplitudes, the vibrational frequency was raised. Figure 8a show the average downward velocities from the $30 \mathrm{~Hz}$ simulations at a range of accelerations: $59.2 \mathrm{~m} / \mathrm{s}^{2}, 7.11 \mathrm{~m} / \mathrm{s}^{2}$, and $178 \mathrm{~m} / \mathrm{s}^{2}$ in Figure 8b, c, and d, respectively. Once again, the average downward velocity of the drop increased with increasing acceleration. There is also one acceleration that was only able to induce rocking motion in the droplet but no motion (i.e., $1.78 \mathrm{~m} / \mathrm{s}^{2}$ ). The acceleration for the rocking droplet at $30 \mathrm{~Hz}$ was close to the rocking droplet case at $10 \mathrm{~Hz}, 1.78 \mathrm{~m} / \mathrm{s}^{2}$ and $1.98 \mathrm{~m} / \mathrm{s}^{2}$ respectively. For both tests, the minimum acceleration tested that produced an average downward velocity was $7.11 \mathrm{~m} / \mathrm{s}^{2}$. In Figure $8 \mathrm{~d}$ at an acceleration of 178 $\mathrm{m} / \mathrm{s}^{2}$, the droplet sheds a portion of itself as it travels down the surface. This is not seen at any other of the simulated frequencies; however, it is also seen in the $197 \mathrm{~m} / \mathrm{s}^{2}$ test case. This phenomenon could be caused by the beginning stages of resonance in the droplet. Equation (10) shows the calculation for resonance frequency proposed by Perez et al. [48].

$$
f_{r}=\sqrt{\frac{4}{5} \frac{\sigma}{\pi \rho V}}
$$

Where $f_{r}$ is the resonance frequency, $\sigma$ is the surface tension of water, $\rho$ is the density of water, and $V$ is the volume of the droplet. The predicted resonance frequency for a 2.6-mm water droplet is $40 \mathrm{~Hz}$. 
Figure 9a shows the average downward velocities over a range of accelerations for $70 \mathrm{~Hz}$, while Figure 9b, c, and d show images from the $197 \mathrm{~m} / \mathrm{s}^{2}, 59.2 \mathrm{~m} / \mathrm{s}^{2}$, and $9.67 \mathrm{~m} / \mathrm{s}^{2}$ acceleration cases, respectively. Similarly, Figure 10a shows the average downward velocities over a range of accelerations for $100 \mathrm{~Hz}$, while Figure 10b, c, and d show images from the $197 \mathrm{~m} / \mathrm{s}^{2}, 59.2 \mathrm{~m} / \mathrm{s}^{2}$, and $7.11 \mathrm{~m} / \mathrm{s}^{2}$ acceleration cases respectively. The lowest tested accelerations for both of these frequencies was $7.11 \mathrm{~m} / \mathrm{s}^{2}$, and similarly to the $10 \mathrm{~Hz}$ and $30 \mathrm{~Hz}$ cases, these droplets experienced ratcheting motion. However, all of these velocities; therefore, the results suggest that the transition from rocking motion to ratcheting motion is a function of acceleration for droplets of the same mass.

\subsection{Analysis}

Since acceleration is key to transitioning from rocking to ratchet motion, three accelerations were tested for each frequency (i.e., $7.11 \mathrm{~m} / \mathrm{s}^{2}, 59.2 \mathrm{~m} / \mathrm{s}^{2}$, and $197 \mathrm{~m} / \mathrm{s}^{2}$ ). The other three tests used the same amplitudes across the frequencies; all tests are shown in Table 1.

Table 1: Test matrix of simulation frequencies, amplitudes, and accelerations

\begin{tabular}{|c|c|c|c|c|c|c|}
\hline Frequency (Hz) & \multicolumn{7}{|c|}{$y$-amplitude $(\mathrm{mm})$ [Acceleration $\left.\left(\mathrm{m} / \mathrm{s}^{2}\right)\right]$} \\
\hline $\mathbf{1 0}$ & $0.1[0.197]$ & $1[1.97]$ & $3.6[7.11]$ & $10[19.7]$ & $30[59.2]$ & $100[197]$ \\
\hline $\mathbf{3 0}$ & $0.1[1.78]$ & $0.4[7.11]$ & - & $3.33[59.2]$ & $10[178]$ & $11.11[197]$ \\
\hline $\mathbf{7 0}$ & $0.0735[7.11]$ & $0.1[9.67]$ & $0.612[59.2]$ & $1[96.7]$ & $2.04[197]$ & $10[967]$ \\
\hline $\mathbf{1 0 0}$ & $0.036[7.11]$ & $0.1[19.7]$ & $0.3[59.2]$ & $1[197]$ & $10[1970]$ & - \\
\hline
\end{tabular}

To determine if the velocity of a droplet is a function of acceleration only, the average downward velocities for the three set accelerations were compared across all frequencies, seen in Figure 11. There is a trend in the $59.2 \mathrm{~m} / \mathrm{s}^{2}$ and $197 \mathrm{~m} / \mathrm{s}^{2}$ accelerations that the average downward velocity will decrease as the frequency is increased from $10 \mathrm{~Hz}$ to $70 \mathrm{~Hz}$ and the $100 \mathrm{~Hz}$ case near the $70 \mathrm{~Hz}$ case. However, for the $7.11 \mathrm{~m} / \mathrm{s}^{2}$ of acceleration, the trend is unclear and the $30 \mathrm{~Hz}$ case 
has the highest average downward velocity; it is likely this may be due to the resonant frequency of the droplet to be approximately $40 \mathrm{~Hz}$, according to the equation (10).

In order to non-dimensionalize the data, the Strouhal number was calculated for the constant accelerations across the four frequencies, equation (11).

$$
S t=\frac{f D}{u}
$$

where $f$ is the frequency, $D$ is the diameter, and $u$ is the average downward velocity. The Strouhal number decreases as the frequency decreases from $100 \mathrm{~Hz}$ to $10 \mathrm{~Hz}$ for the $59.2 \mathrm{~m} / \mathrm{s}^{2}$ and $197 \mathrm{~m} / \mathrm{s}^{2}$ acceleration cases. For the $7.11 \mathrm{~m} / \mathrm{s}^{2}$ acceleration case, the $30 \mathrm{~Hz}$ case has the lowest Strouhal number instead of $10 \mathrm{~Hz}$, as seen in Figure 12. This is likely due to the large average downward velocity caused by the proximity to resonance.

These differences in average downward velocity across the different frequencies shows that, although acceleration plays an important role, the velocity of the droplets is not solely determined by the acceleration. After it was determined that acceleration did not trend solely with the velocity, the average downward velocities of the vibrations the same vibration amplitudes were compared, seen in Figure 13. The average downward velocities all have the same trend for all three amplitudes, with the velocity decreasing as the frequency decreases from $100 \mathrm{~Hz}$ to $10 \mathrm{~Hz}$. Average downward velocities for each frequency and amplitude are plotted in Figure 14, demonstrating the proportional effects of amplitude and higher-order effects of frequency.

\section{Conclusions}

Simulations were conducted for a 2.6-mm water droplet on a vertical, hydrophobic surface and results were initially compared to two experimental cases for validation purposes. Excellent agreement was observed between predicted velocities between experiments and simulations for a 
ratcheting case at $30 \mathrm{~Hz}$ [i.e., $16 \mathrm{~mm} / \mathrm{s}$ (simulation) and $15 \mathrm{~mm} / \mathrm{s}$ (experiment)] and an ejecting case at $100 \mathrm{~Hz}$ [i.e., $40 \mathrm{~mm} / \mathrm{s}$ (simulation) and $41 \mathrm{~mm} / \mathrm{s}$ (experiment) at $f=100 \mathrm{~Hz}$ ]. The lattice Boltzmann method was shown to resolve droplet motion for this moving contact line, multi-phase problem.

Following experimental validation, simulations were conducted for a wide range of frequencies (i.e., $10-\mathrm{Hz}$ ) and $\mathrm{x}$-amplitudes (i.e., $0-$ ) and $\mathrm{y}$-amplitudes (i.e., $0.036-100 \mathrm{~mm}$ ). Droplet motion was found to be a function of both frequency and amplitude. As a result of applied vibrations, droplet rocking, ratchet, and ejection modes were observed. Rocking and ratcheting both included the rocking motion of a droplet; however, in ratcheting, motion occurred once the droplet overcame contact angle hysteresis whereas rocking droplets were stationary. At low accelerations (e.g., $<7 \mathrm{~m} / \mathrm{s}^{2}$ ), rocking occurred and the droplet was stationary, whereas higher accelerations (e.g., $>7 \mathrm{~m} / \mathrm{s}^{2}$ ) promoted higher droplet velocities during ratcheting. The droplet ejection mode was only observed for cases with applied $x$ - and $y$-direction vibrations. Future work will investigate the impacts of droplet motion on cooling tower water collection.

\section{Funding information}

The authors gratefully acknowledge the support of National Science Foundation grant number 1603737.

\section{Nomenclature}

$\begin{array}{ll}A & \text { x-direction amplitude } \\ B & \text { y-direction amplitude } \\ D & \text { Diameter } \\ F & \text { probability distribution function } \\ M_{i j} & \text { transformation matrix }\end{array}$




\begin{tabular}{|c|c|}
\hline$\hat{S}_{i j}$ & diagonal relaxation matrix \\
\hline$S_{v}$ & stability parameter \\
\hline$V$ & volume \\
\hline$C_{s}$ & speed of sound \\
\hline e & velocity vector \\
\hline$f$ & frequency \\
\hline$m$ & number of velocity directions \\
\hline$n$ & dimension of problem \\
\hline$t$ & time \\
\hline$u$ & macroscopic velocity \\
\hline$x$ & $\mathrm{x}$-direction position \\
\hline$y$ & $\mathrm{y}$-direction position \\
\hline$z$ & z-direction position \\
\hline \multicolumn{2}{|c|}{ Greek } \\
\hline$\Omega$ & collision operator \\
\hline$\delta$ & resolved scale \\
\hline$\Delta t$ & time step \\
\hline$\mu$ & raw moment \\
\hline$\sigma$ & surface tension \\
\hline$\rho$ & density \\
\hline$\tau$ & relaxation time \\
\hline
\end{tabular}




\section{Sub/Super scripts}

$\begin{array}{ll}\text { MRT } & \text { multiple relaxation time } \\ i & \text { at equilibrium } \\ k & \text { direction vector } \\ l & \text { order of moment in x-direction } \\ m & \text { order of moment in y-direction } \\ r & \text { order of moment in z-direction } \\ & \text { resonance frequency }\end{array}$

\section{References}

[1] Hussey, K., and Pittock, J., 2012, "The energy-water nexus: Managing the links between energy and water for a sustainable future," Ecology and Society, 17(1).

[2] DeNooyer, T. A., Peschel, J. M., Zhang, Z., and Stillwell, A. S., 2016, "Integrating water resources and power generation: the energy-water nexus in Illinois," Applied energy, 162, pp. 363-371.

[3] Lubega, W. N., and Stillwell, A. S., 2018, "Maintaining electric grid reliability under hydrologic drought and heat wave conditions," Applied energy, 210, pp. 538-549.

[4] Tidwell, V. C., Kobos, P. H., Malczynski, L. A., Klise, G., and Castillo, C. R., 2011, "Exploring the water-thermoelectric power nexus," Journal of Water Resources Planning and Management, 138(5), pp. 491-501.

[5] Maupin, M. A., Kenny, J. F., Hutson, S. S., Lovelace, J. K., Barber, N. L., and Linsey, K. S., 2014, "Estimated use of water in the United States in 2010," No. 2330-5703, US Geological Survey.

[6] Benn, S. P., Poplaski, L. M., Faghri, A., and Bergman, T. L., 2016, "Analysis of thermosyphon/heat pipe integration for feasibility of dry cooling for thermoelectric power generation," Applied Thermal Engineering, 104, pp. 358-374.

[7] Shoele, K., and Mittal, R., 2016, "Energy harvesting by flow-induced flutter in a simple model of an inverted piezoelectric flag," Journal of Fluid Mechanics, 790, pp. 582-606.

[8] Ghosh, R., Ray, T. K., and Ganguly, R., 2015, "Cooling tower fog harvesting in power plants-A pilot study," Energy, 89, pp. 1018-1028.

[9] Damak, M., and Varanasi, K. K., 2018, "Electrostatically driven fog collection using space charge injection," Science advances, 4(6), p. eaao5323. 
[10] Fessehaye, M., Abdul-Wahab, S. A., Savage, M. J., Kohler, T., Gherezghiher, T., and Hurni, H., 2014, "Fog-water collection for community use," Renewable and Sustainable Energy Reviews, 29, pp. 52-62.

[11] Jaen, M. V. M., 2002, "Fog water collection in a rural park in the Canary Islands (Spain)," Atmospheric Research, 64(1), pp. 239-250.

[12] Olivier, J., and De Rautenbach, C., 2002, "The implementation of fog water collection systems in South Africa," Atmospheric Research, 64(1), pp. 227-238.

[13] Estrela, M. J., Valiente, J. A., Corell, D., Fuentes, D., and Valdecantos, A., 2009, "Prospective use of collected fog water in the restoration of degraded burned areas under dry Mediterranean conditions," Agricultural and forest meteorology, 149(11), pp. 1896-1906.

[14] Quéré, D., Azzopardi, M.-J., and Delattre, L., 1998, "Drops at rest on a tilted plane," Langmuir, 14(8), pp. $2213-2216$.

[15] Al-Sharafi, A., Yilbas, B. S., and Ali, H., 2017, "Water Droplet Adhesion on Hydrophobic Surfaces: Influence of Droplet Size and Inclination Angle of Surface on Adhesion Force," Journal of Fluids Engineering, 139(8), p. 081302.

[16] Daniel, S., Sircar, S., Gliem, J., and Chaudhury, M. K., 2004, "Ratcheting motion of liquid drops on gradient surfaces," Langmuir, 20(10), pp. 4085-4092.

[17] Sommers, A., Brest, T., and Eid, K., 2013, "Topography-based surface tension gradients to facilitate water droplet movement on laser-etched copper substrates," Langmuir, 29(38), pp. 12043-12050.

[18] Benilov, E., and Billingham, J., 2011, "Drops climbing uphill on an oscillating substrate," Journal of Fluid mechanics, 674, pp. 93-119.

[19] Brunet, P., Eggers, J., and Deegan, R., 2007, "Vibration-induced climbing of drops," Physical review letters, 99(14), p. 144501.

[20] Chaudhury, M. K., Chakrabarti, A., and Daniel, S., 2015, "Generation of motion of drops with interfacial contact," Langmuir, 31(34), pp. 9266-9281.

[21] Daniel, S., Chaudhury, M. K., and De Gennes, P.-G., 2005, "Vibration-actuated drop motion on surfaces for batch microfluidic processes," Langmuir, 21(9), pp. 4240-4248.

[22] Dong, L., Chaudhury, A., and Chaudhury, M., 2006, "Lateral vibration of a water drop and its motion on a vibrating surface," The European Physical Journal E, 21(3), pp. 231-242.

[23] Mettu, S., and Chaudhury, M. K., 2011, "Motion of liquid drops on surfaces induced by asymmetric vibration: role of contact angle hysteresis," Langmuir, 27(16), pp. 10327-10333.

[24] Noblin, X., Buguin, A., and Brochard-Wyart, F., 2009, "Vibrations of sessile drops," The European Physical Journal Special Topics, 166(1), pp. 7-10.

[25] Noblin, X., Kofman, R., and Celestini, F., 2009, "Ratchetlike motion of a shaken drop," Physical review letters, 102(19), p. 194504. 
[26] Mettu, S., and Chaudhury, M. K., 2008, "Motion of drops on a surface induced by thermal gradient and vibration," Langmuir, 24(19), pp. 10833-10837.

[27] Huber, R. A., and Derby, M. M., "Droplet Coalescence and Departure on a Vibrating Film During Humid Air Condensation," Proc. ASME 2017 15th International Conference on Nanochannels, Microchannels, and Minichannels, American Society of Mechanical Engineers, pp. V001T004A005-V001T004A005.

[28] Bormashenko, E., Pogreb, R., Whyman, G., Bormashenko, Y., and Erlich, M., 2007, "Vibration-induced Cassie-Wenzel wetting transition on rough surfaces," Applied physics letters, 90(20), p. 201917.

[29] Mettu, S., and Chaudhury, M. K., 2010, "Stochastic relaxation of the contact line of a water drop on a solid substrate subjected to white noise vibration: roles of hysteresis," Langmuir, 26(11), pp. 8131-8140.

[30] Shastry, A., Case, M. J., and Böhringer, K. F., 2006, "Directing droplets using microstructured surfaces," Langmuir, 22(14), pp. 6161-6167.

[31] Liu, H., Ju, Y., Wang, N., Xi, G., and Zhang, Y., 2015, "Lattice Boltzmann modeling of contact angle and its hysteresis in two-phase flow with large viscosity difference," Physical Review E, 92(3), p. 033306.

[32] Srivastava, S., ten Thije Boonkkamp, J., and Toschi, F., 2014, "Lattice Boltzmann method for contact line dynamics," PhD thesis, Eindhoven University of Technology.

[33] Wu, T.-C., 2015, "Two-Phase Flow in Microchannels with Application to PEM Fuel Cells."

[34] Malgarinos, I., Nikolopoulos, N., Marengo, M., Antonini, C., and Gavaises, M., 2014, "VOF simulations of the contact angle dynamics during the drop spreading: Standard models and a new wetting force model," Advances in colloid and interface science, 212, pp. 1-20.

[35] Hao, L., and Cheng, P., 2009, "Lattice Boltzmann simulations of liquid droplet dynamic behavior on a hydrophobic surface of a gas flow channel," Journal of power sources, 190(2), pp. 435-446.

[36] Bao, Y. B., and Meskas, J., 2011, "Lattice Boltzmann method for fluid simulations," Department of Mathematics, Courant Institute of Mathematical Sciences, New York University.

[37] Kang, X., Tang, W., and Liu, S., 2016, "Lattice Boltzmann Method for Simulating Disturbed Hemodynamic Characteristics of Blood Flow in Stenosed Human Carotid Bifurcation," Journal of Fluids Engineering, 138(12), p. 121104.

[38] Murdock, J. R., Ibrahim, A., and Yang, S.-L., 2018, "An Efficient Method of Generating and Characterizing Filter Substrates for Lattice Boltzmann Analysis," Journal of Fluids Engineering, 140(4), p. 041203.

[39] Wafik, A., Fethi, A., Keirsbulck, L., and Sassi, B. N., 2015, "Experimental and Numerical Investigations Using Lattice Boltzmann Method to Study Shedding Vortices in an Unsteady Confined Flow Around an Obstacle," Journal of Fluids Engineering, 137(10), p. 101203. 
[40] Yuan, P., and Schaefer, L., 2006, "A thermal lattice Boltzmann two-phase flow model and its application to heat transfer problems_-part 1. Theoretical foundation," Journal of Fluids Engineering, 128(1), pp. 142-150.

[41] Yuan, P., and Schaefer, L., 2006, "A thermal lattice Boltzmann two-phase flow model and its application to heat transfer problems_-part 2. Integration and validation," Journal of fluids engineering, 128(1), pp. 151-156.

[42] XFlow, S., 2018, "XFlow 2018 Theory Guide."

[43] Shih, T.-H., Povinelli, L. A., Liu, N.-S., Potapczuk, M. G., and Lumley, J., 1999, "A generalized wall function."

[44] Chen, X., Doughramaji, N., Betz, A. R., and Derby, M. M., 2017, "Droplet ejection and sliding on a flapping film," AIP Advances, 7(3), p. 035014.

[45] Yang, A.-S., and Tsai, W.-M., 2006, "Ejection process simulation for a piezoelectric microdroplet generator," Journal of fluids engineering, 128(6), pp. 1144-1152.

[46] Castillo, J. E., Weibel, J. A., and Garimella, S. V., 2015, "The effect of relative humidity on dropwise condensation dynamics," International Journal of Heat and Mass Transfer, 80, pp. 759-766.

[47] Leach, R., Stevens, F., Langford, S., and Dickinson, J., 2006, "Dropwise condensation: experiments and simulations of nucleation and growth of water drops in a cooling system," Langmuir: the ACS journal of surfaces and colloids, 22(21), p. 8864.

[48] Perez, M., Brechet, Y., Salvo, L., Papoular, M., and Suery, M., 1999, "Oscillation of liquid drops under gravity: Influence of shape on the resonance frequency," EPL (Europhysics Letters), 47(2), p. 189. 


\section{Figure captions}

Figure 1: Experimentally-determined a) receding $\left(60^{\circ}\right)$ and b) advancing $\left(120^{\circ}\right)$ contact angles of a 2.6-mm water droplet on a vertical hydrophobic surface

Figure 2: Grid independence study using kinetic energy

Figure 3: Droplet motion of a) an experimental droplet and b) simulated droplet at $30 \mathrm{~Hz}$, X-amplitude $\pm 0.1 \mathrm{~mm}$, y-amplitude $\pm 0.2 \mathrm{~mm}$

Figure 4: Droplet motion for a) an experimental droplet and b) simulated droplet at 100

Hz, x-amplitude $\pm 0.8 \mathrm{~mm}$, y-amplitude $\pm 0.3 \mathrm{~mm}$

Figure 5: $30 \mathrm{~Hz}$ simulated droplet motion for a) $\mathrm{x}$ - and y-vibrational forces and b) only $\mathrm{y}$ vibrational forces (x-amplitude $\pm 0.1 \mathrm{~mm}$, y-amplitude $\pm 0.2 \mathrm{~mm}$ )

Figure 6: $100 \mathrm{~Hz}$ simulated droplet motion for a) x- and y-vibrational forces b) only y-vibrational forces (x-amplitude $\pm 0.8 \mathrm{~mm}, \mathrm{y}$-amplitude $\pm 0.3 \mathrm{~mm}$ )

Figure 7: $10 \mathrm{~Hz}$ simulated droplet a) velocities for given accelerations and simulations with applied accelerations of b) $7.11 \mathrm{~m} / \mathrm{s}^{2}$ c) $0.197 \mathrm{~m} / \mathrm{s} 2$, and d) $59.2 \mathrm{~m} / \mathrm{s} 2$ images

Figure 8: a) Velocities of simulated droplets at $30 \mathrm{~Hz}$ simulated droplet and accelerations of b) $59.2 \mathrm{~m} / \mathrm{s} 2$, c) $7.11 \mathrm{~m} / \mathrm{s} 2$, and d) $178 \mathrm{~m} / \mathrm{s} 2$

Figure 9: $70 \mathrm{~Hz}$ simulated droplet a) velocities for given accelerations b) $197 \mathrm{~m} / \mathrm{s} 2$ images c) 59.2 m/s2 images d) $9.67 \mathrm{~m} / \mathrm{s} 2$ images

Figure 10: $100 \mathrm{~Hz}$ simulated droplet a) velocities for given accelerations b) $197 \mathrm{~m} / \mathrm{s} 2$ images c) $59.2 \mathrm{~m} / \mathrm{s} 2$ images d) $7.11 \mathrm{~m} / \mathrm{s} 2$ images

Figure 11: Average downward velocities for constant accelerations across different frequencies

Figure 12: Strouhal number for constant accelerations across different frequencies

Figure 13: Average downward velocities for constant amplitudes across different frequencies

Figure 14: Three-dimensional plot of velocity vs amplitude and frequency 


\section{Figures}

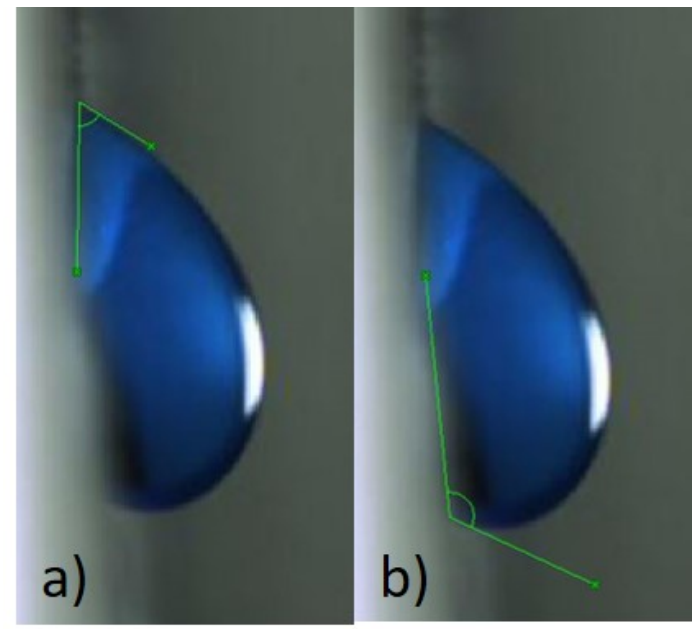

Figure 1: Experimentally-determined a) receding $\left(60^{\circ}\right)$ and b) advancing $\left(120^{\circ}\right)$ contact angles of a 2.6-mm water droplet on a vertical hydrophobic surface
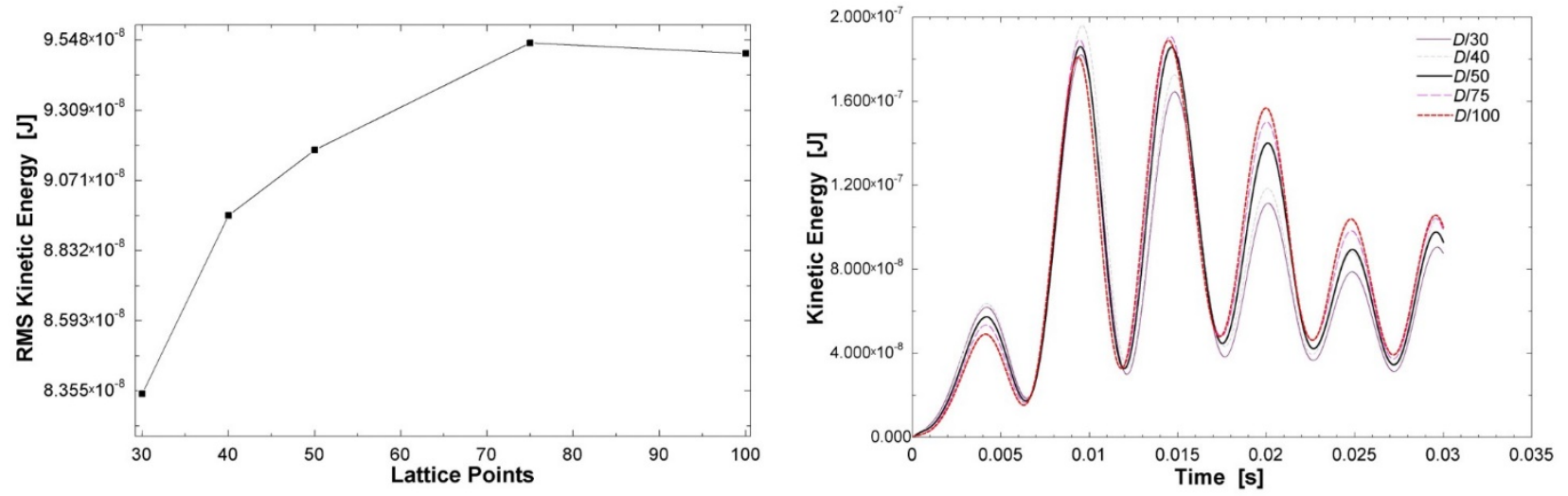

Figure 2: Grid independence study using kinetic energy, (left) root mean square kinetic energy over 0.03 seconds and (right) kinetic energy with time 


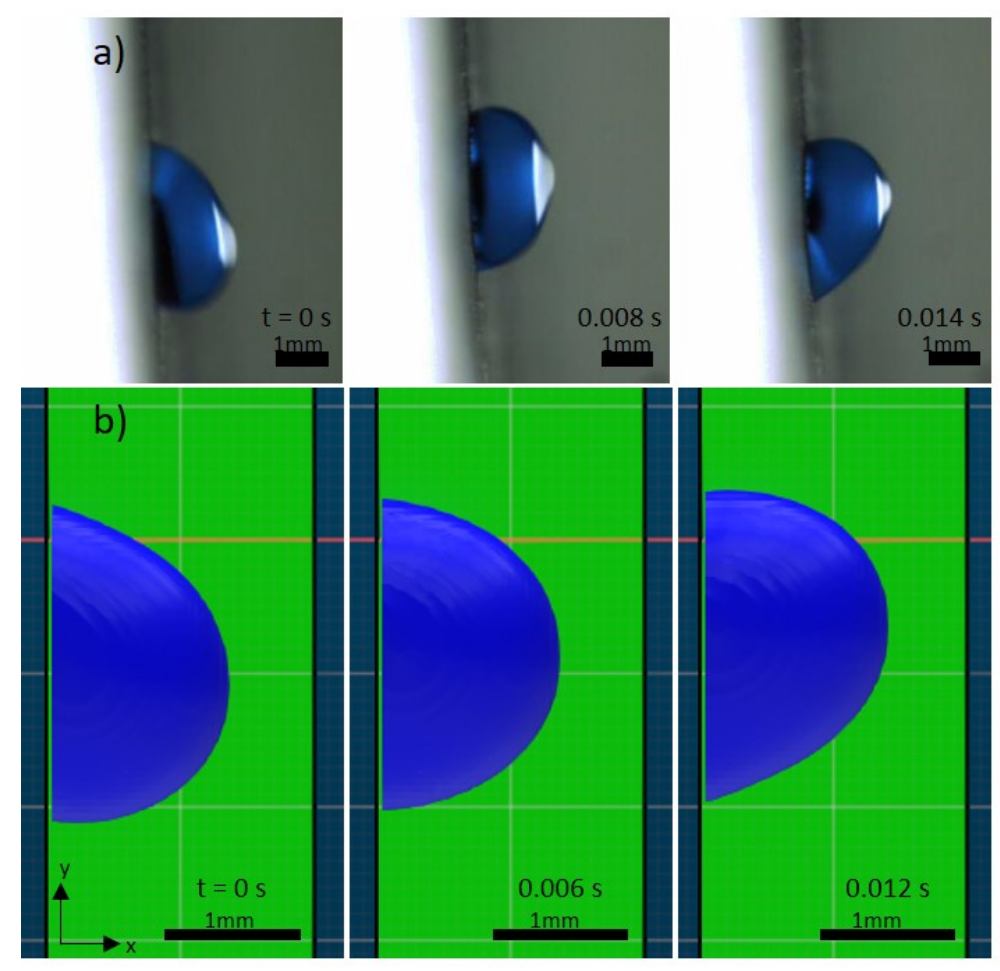

Figure 3: Droplet motion of a) an experimental droplet and b) simulated droplet at $30 \mathrm{~Hz}$, $x$-amplitude $\pm 0.1 \mathrm{~mm}, y$-amplitude $\pm 0.2 \mathrm{~mm}$ 


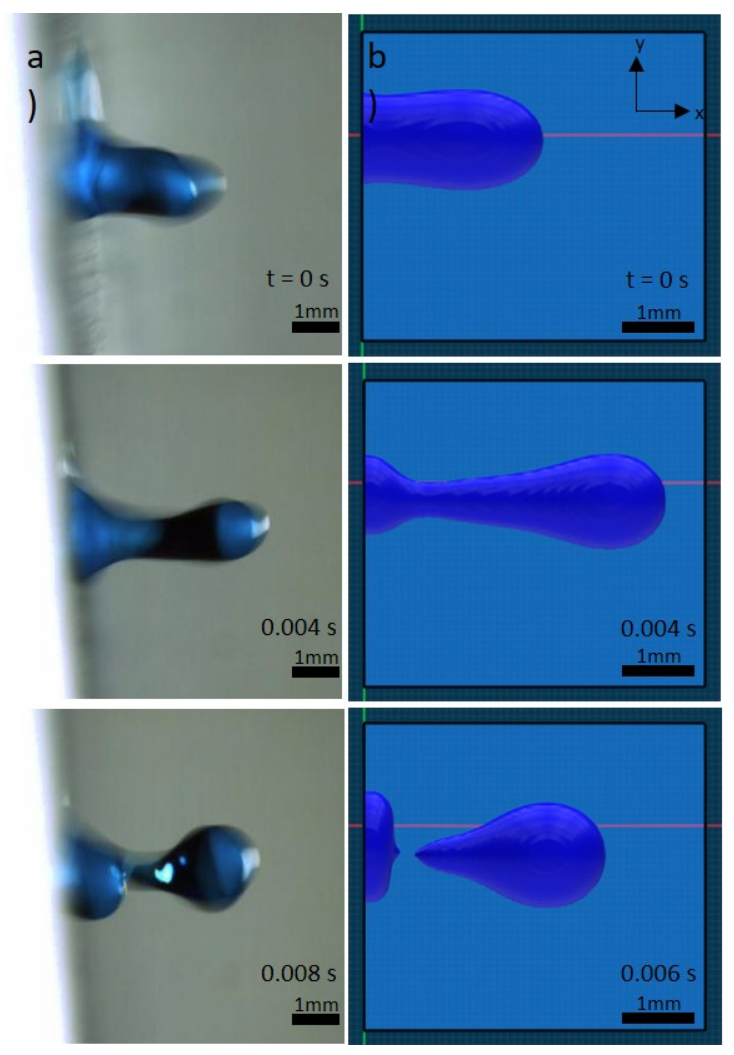

Figure 4: Droplet motion for a) an experimental droplet and b) simulated droplet at $100 \mathrm{~Hz}, x$-amplitude $\pm 0.4 \mathrm{~mm}, y$-amplitude $\pm 0.15 \mathrm{~mm}$ 


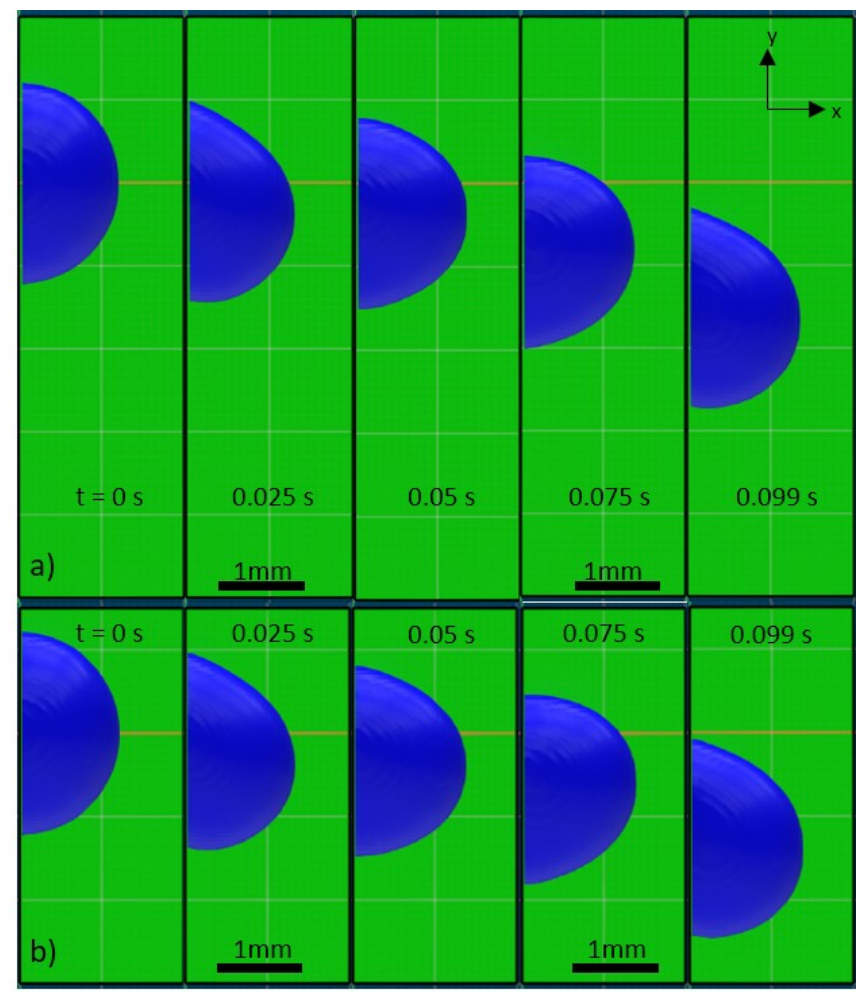

Figure 5: $30 \mathrm{~Hz}$ simulated droplet motion for a) $x$-and $y$-vibrational forces and b) only $y$ vibrational forces ( $x$-amplitude $\pm 0.1 \mathrm{~mm}, y$-amplitude $\pm 0.2 \mathrm{~mm}$ )

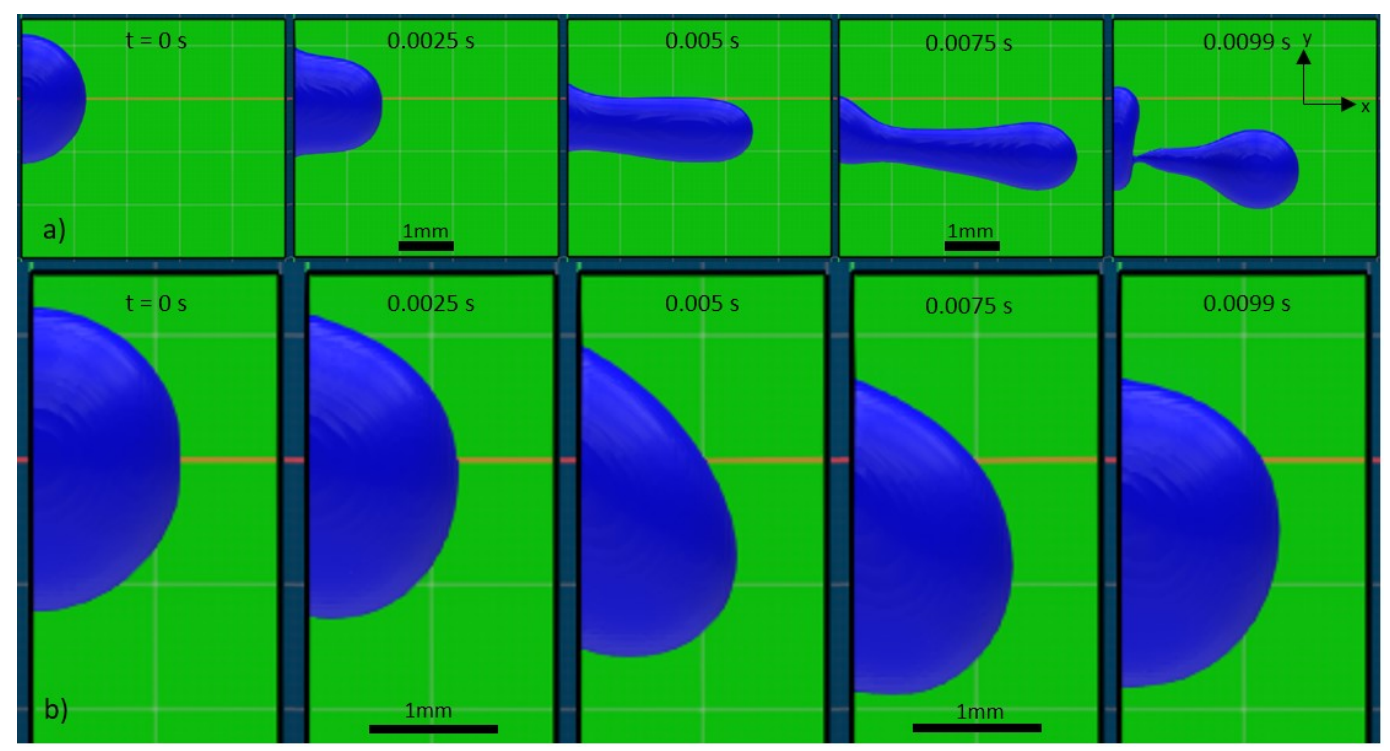

Figure 6: $100 \mathrm{~Hz}$ simulated droplet motion for a) $x$-and $y$-vibrational forces b) only $y$ vibrational forces ( $x$-amplitude $\pm 0.4 \mathrm{~mm}, y$-amplitude $\pm 0.15 \mathrm{~mm}$ ) 

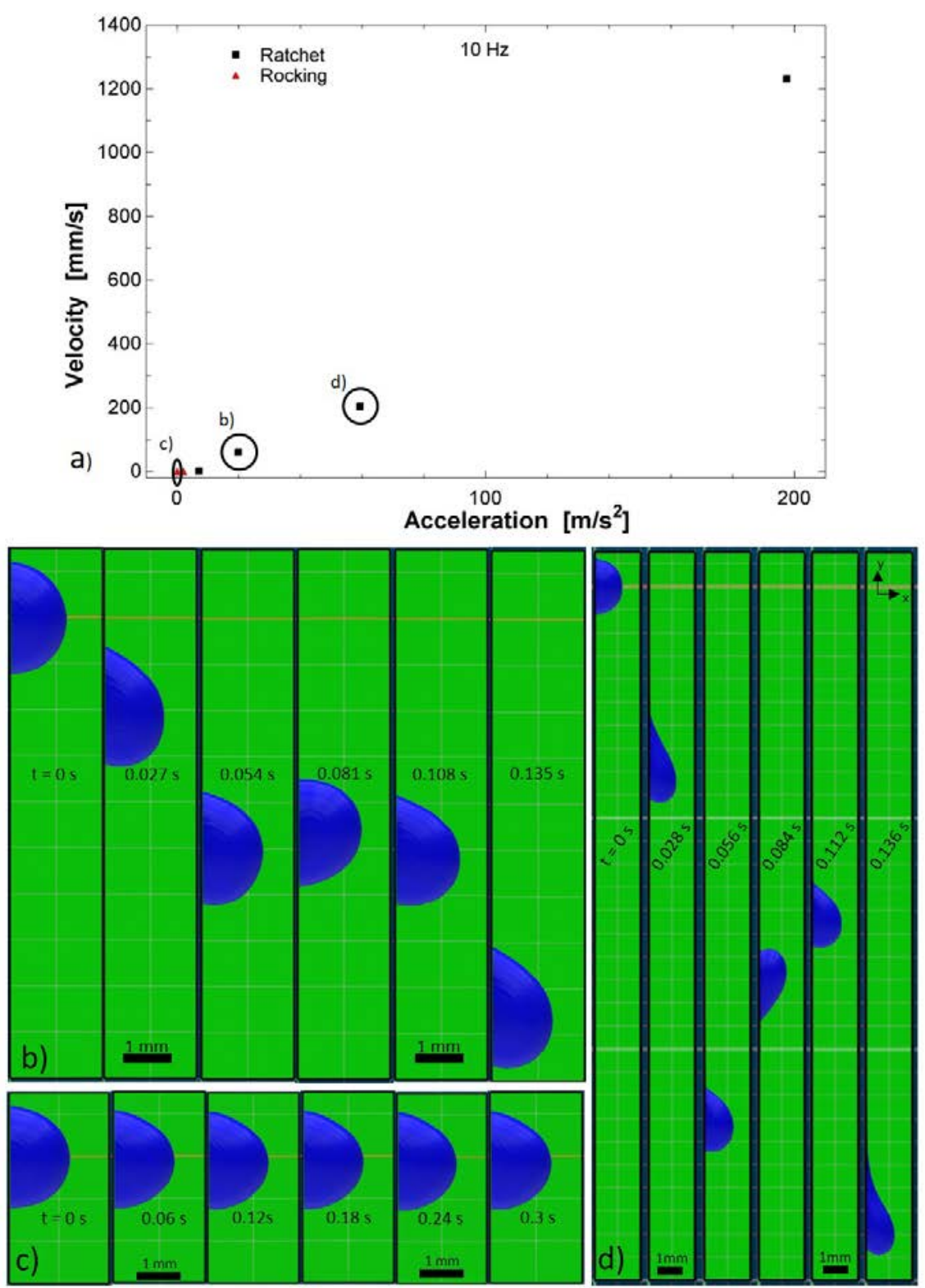

Figure 7: $10 \mathrm{~Hz}$ simulated droplet a) velocities for given accelerations and simulations with applied accelerations of b) $7.11 \mathrm{~m} / \mathrm{s}^{2}$ c) $0.197 \mathrm{~m} / \mathrm{s}^{2}$, and d) $59.2 \mathrm{~m} / \mathrm{s}^{2}$ images 


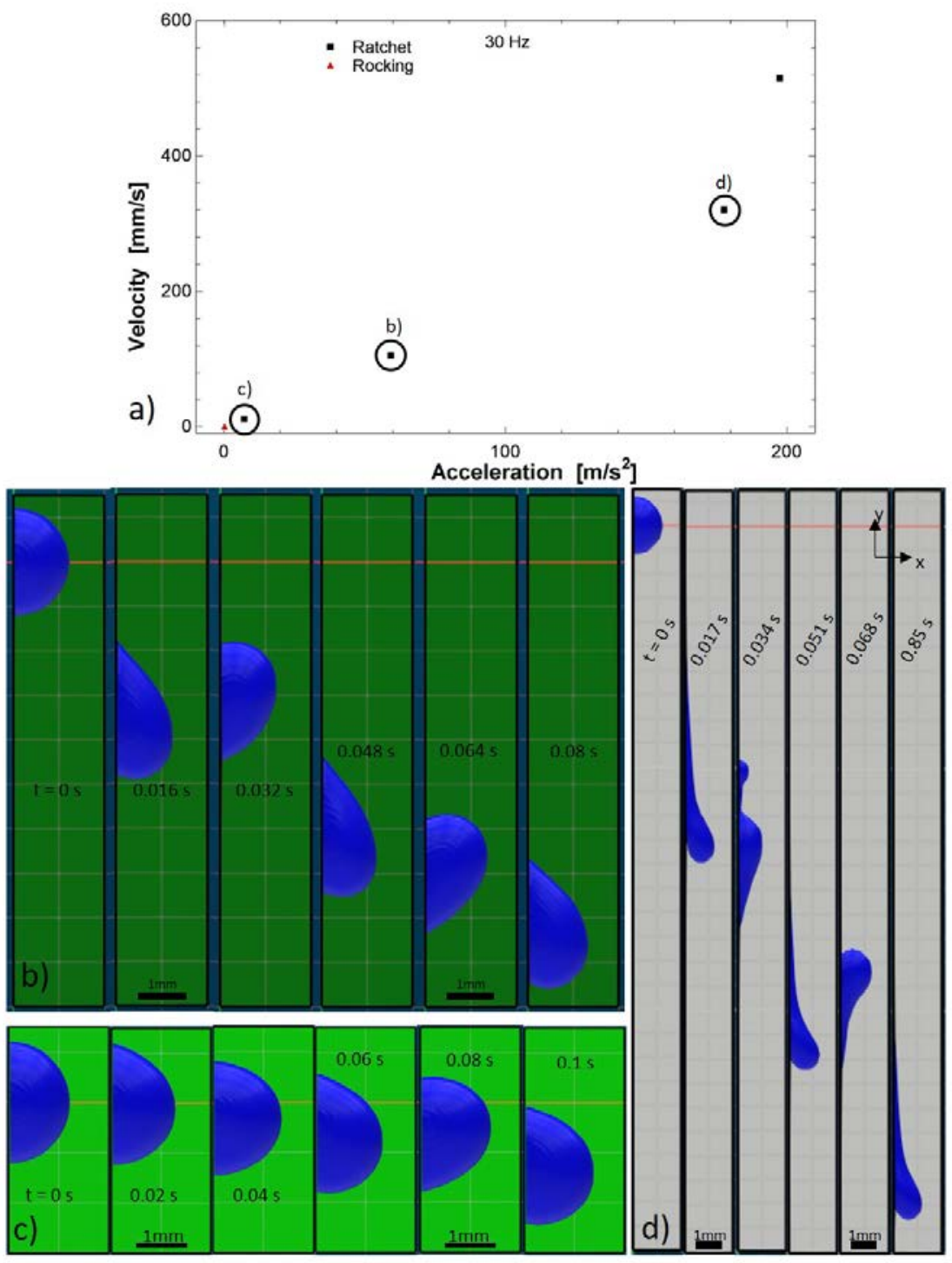

Figure 8: a) Velocities of simulated droplets at $30 \mathrm{~Hz}$ simulated droplet and accelerations of b) $59.2 \mathrm{~m} / \mathrm{s}^{2}$, c) $7.11 \mathrm{~m} / \mathrm{s}^{2}$, and d) $178 \mathrm{~m} / \mathrm{s}^{2}$ 

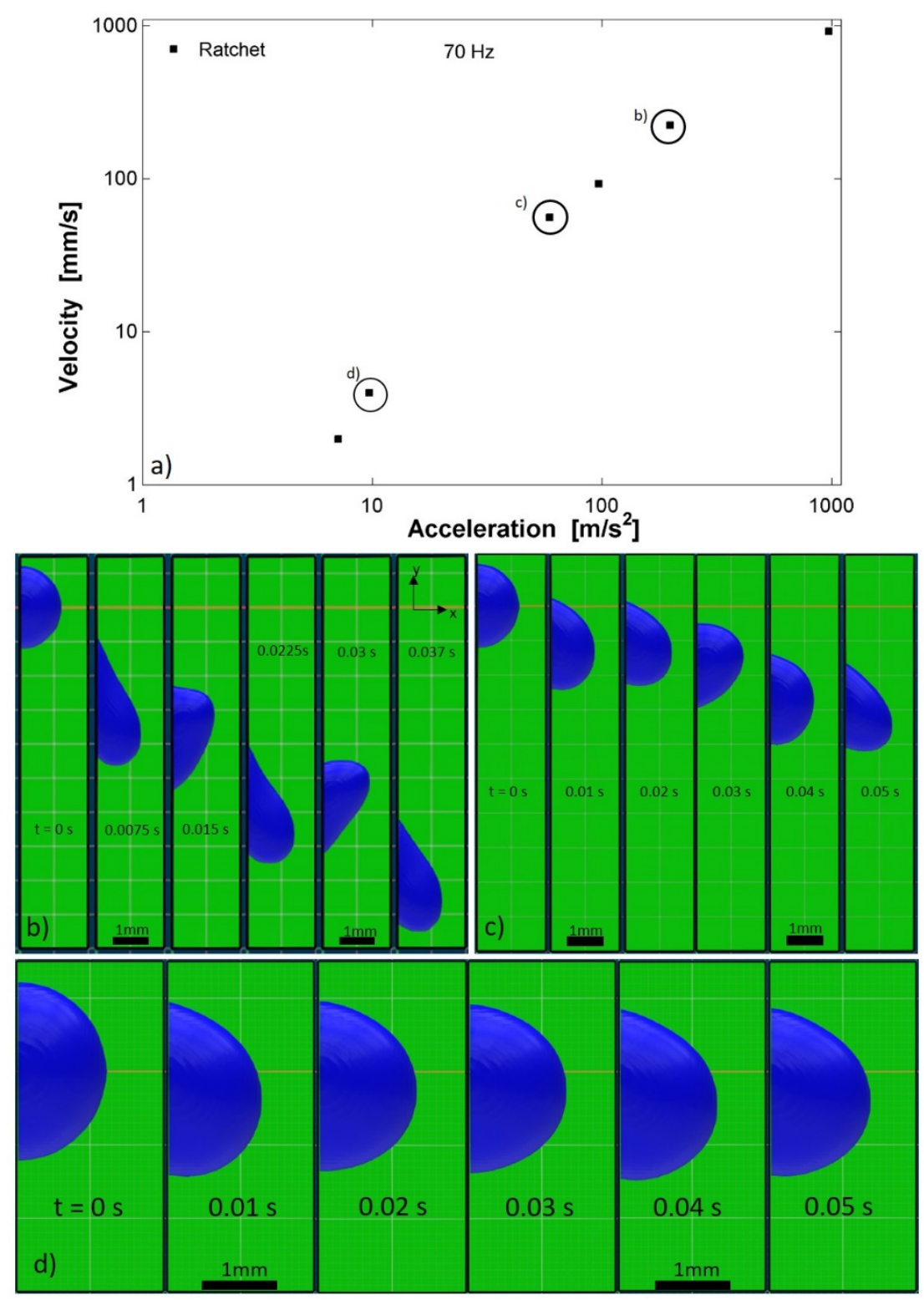

Figure 9: $70 \mathrm{~Hz}$ simulated droplet a) velocities for given accelerations b) $197 \mathrm{~m} / \mathrm{s}^{2}$ images c) $59.2 \mathrm{~m} / \mathrm{s}^{2}$ images d) $9.67 \mathrm{~m} / \mathrm{s}^{2}$ images 


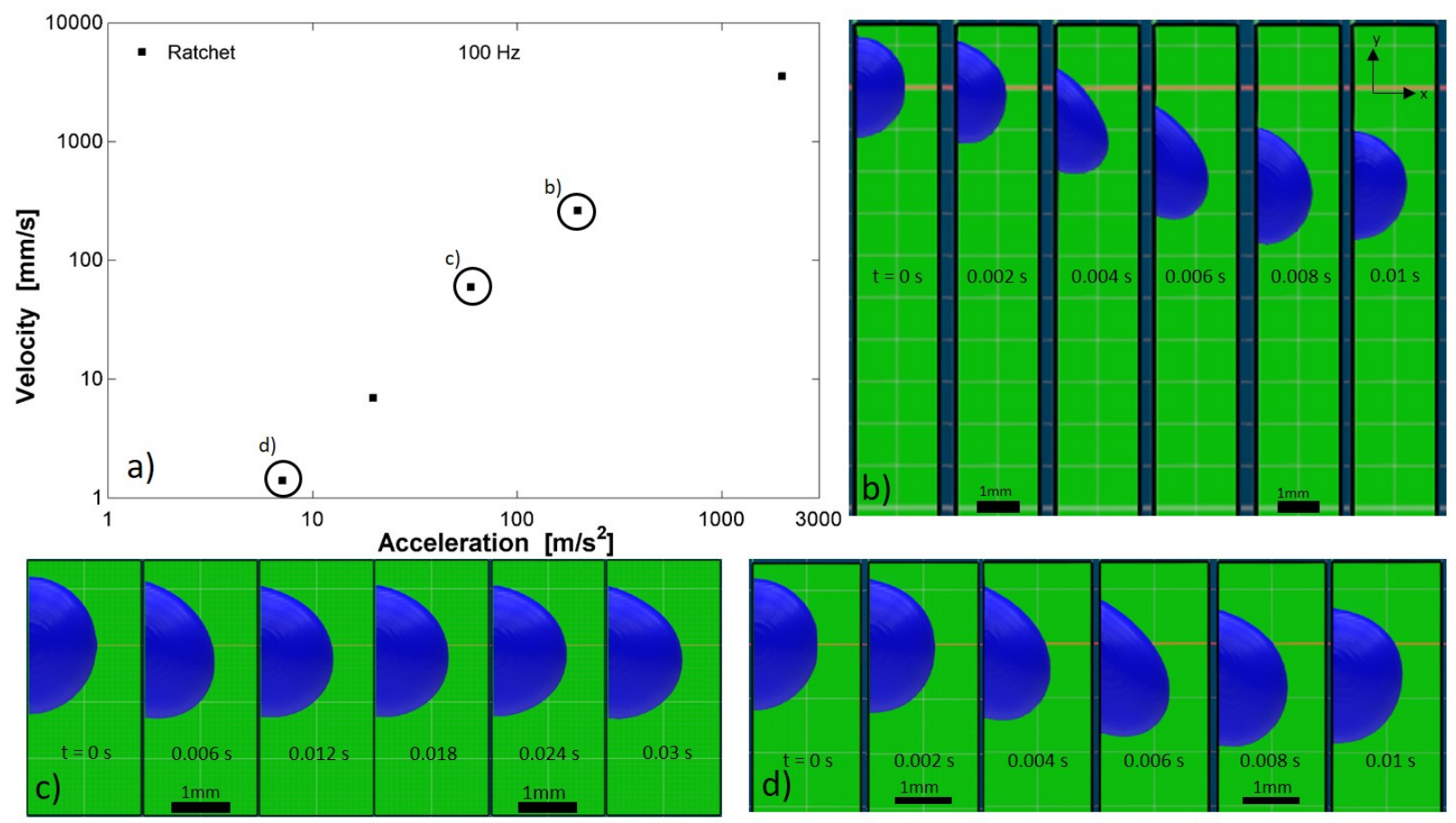

Figure 10: $100 \mathrm{~Hz}$ simulated droplet a) velocities for given accelerations b) $197 \mathrm{~m} / \mathrm{s}^{2}$ images c) $59.2 \mathrm{~m} / \mathrm{s}^{2}$ images d) $7.11 \mathrm{~m} / \mathrm{s}^{2}$ images

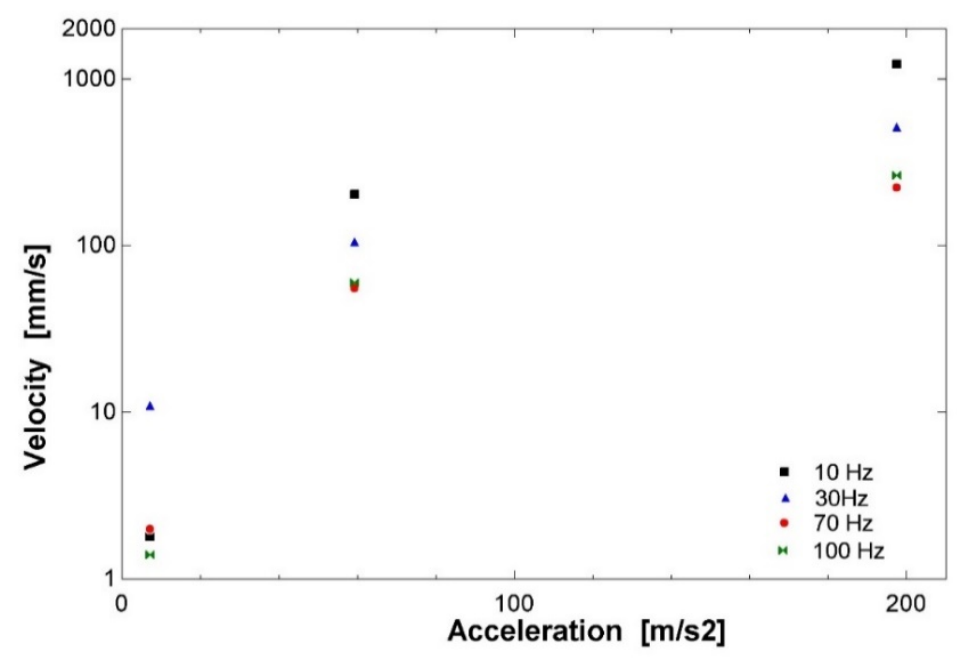

Figure 11: Average downward velocities for constant accelerations across different frequencies 


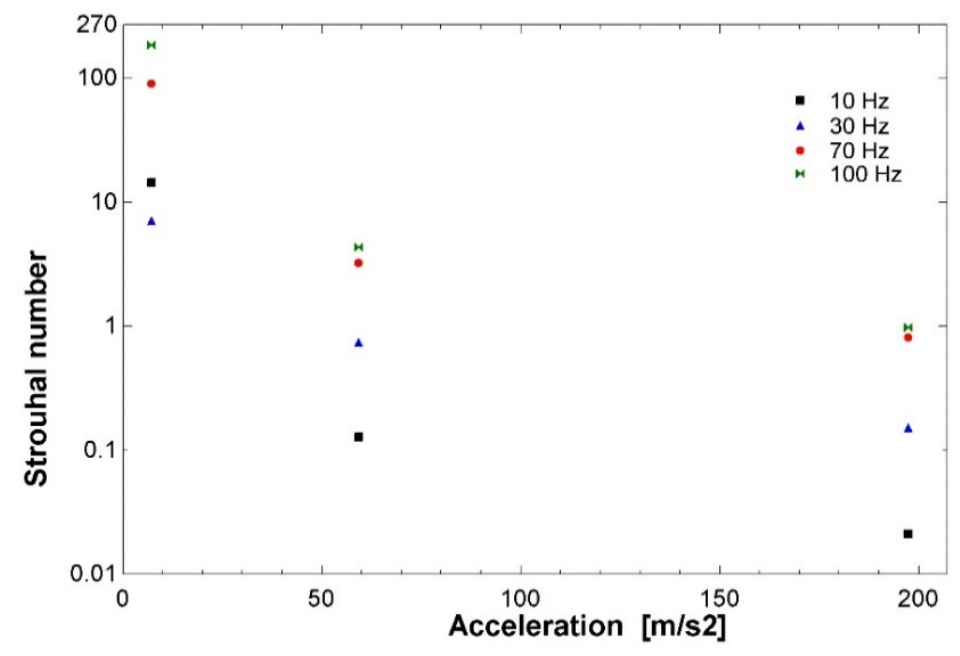

Figure 12: Strouhal number for constant accelerations across different frequencies

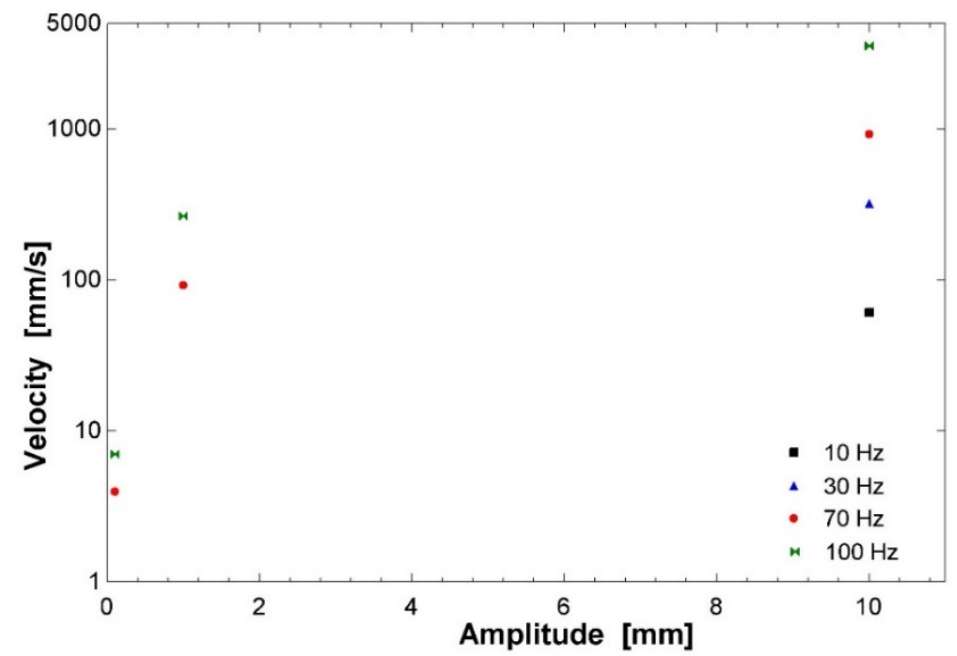

Figure 13: Average downward velocities for constant amplitudes across different frequencies 


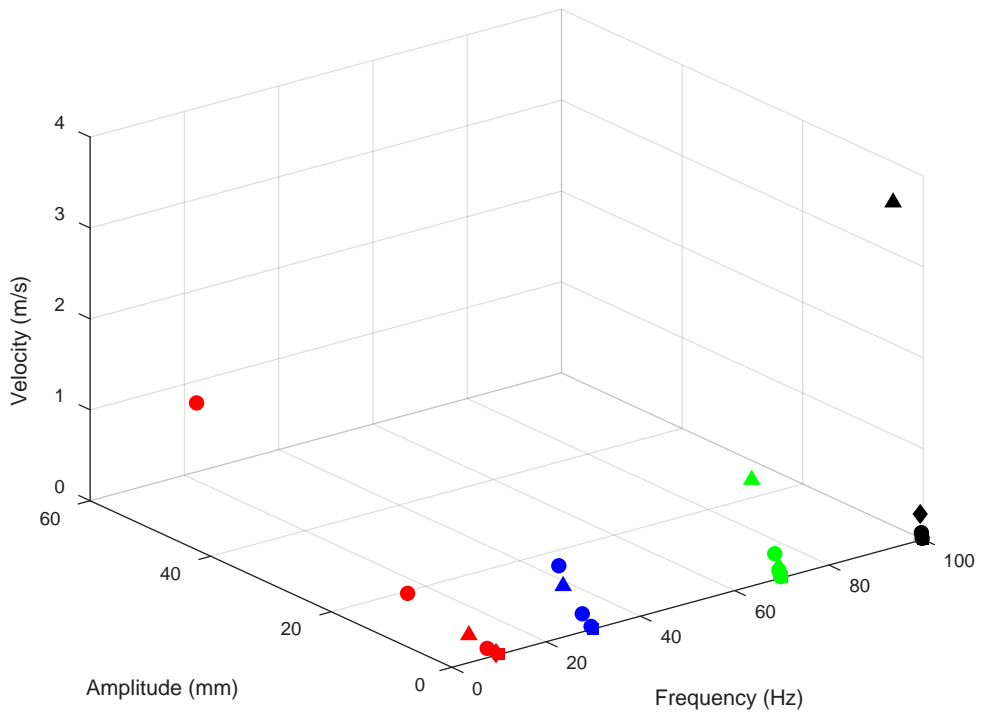

Figure 14: Three-dimensional plot of velocity vs amplitude and frequency

(C) 2018 ASME. This manuscript version is made available under the CC-BY 4.0 license https://creativecommons.org/licenses/by/4.0/ 


\section{American Society of Mechanical Engineers}

SETTING THE STANDARD

\section{ASME Accepted Manuscript Repository}

\section{Institutional Repository Cover Sheet}

\begin{tabular}{cc} 
Melanie & Derby \\
\hline First & Last
\end{tabular}

ASME Paper Title: Vibration-Enhanced Droplet Motion Modes: Simulations of Rocking, Ratcheting, Ratcheting With Breakup, and Ejection

Authors: $\quad$ Ryan A. Huber, Matthew Campbell, Nicole Doughramaji and Melanie M. Derby

ASME Journal Title: Journal of Fluids Engineering

Volume/Issue $141(7)$ Date of Publication (VOR* Online) Jan 07, 2019_

ASME Digital Collection URL: https://fluidsengineering.asmedigitalcollection.asme.org/article.aspx?articleid=27164

DOI:

*VOR (version of record) 